\title{
Observaciones sobre el léxico del español de Yucatán (1650-1800)*
}

\author{
Observations on the lexicon of the Spanish \\ of the Yucatan (1650-1800)
}

\author{
Mariano Quirós García \\ Instituto de Lengua, Literatura y Antropología \\ CCHS-CSIC \\ José Luis Ramírez Luengo \\ Universidad Autónoma de Querétaro
}

\begin{abstract}
RESUMEN: A pesar de su indudable interés por múltiples motivos, el español yucateco no ha sido todavía suficientemente estudiado, y esta carencia es especialmente marcada desde el punto de vista histórico. Teniendo en cuenta este hecho, el presente trabajo pretende aportar algunos datos que sirvan para ir paliando tal situación por medio del análisis del léxico empleado en la zona entre 1650 y 1800, y más en concreto de todos aquellos elementos que, por diversos motivos $-\mathrm{y}$ desde diferentes puntos de vista - se pueden calificar como americanismos, con el propósito de analizar la configuración léxica del español yucateco en el periodo seleccionado y aportar una primera descripción del vocabulario que se emplea en la región en estos momentos.
\end{abstract}

Palabras clave: historia del español de América, léxico, español de Yucatán, siglo XVIII, americanismo.

ABSTRACT: Despite of its interest, Yucatan Spanish has not been studied yet in a very profond way, and this situation is specially remarkable from a historical point of view. This paper aims to provide some data to change this situation: it studies Yucatan Spanish lexicon used between 1650 and 1800 focusing in americanisms, in order to

* Este trabajo forma parte de los resultados del proyecto de investigación "Nuevo Diccionario Etimológico de la Lengua Española" (FFI2012-31897), financiado por el Ministerio de Economía y Competitividad de España. Agradecemos a José Antonio Pascual su atenta lectura y sus inestimables observaciones. 
analyse lexical configuration of this variety, and also to obtain a first description of vocabulary witten in the región during this period.

Keywords: history of latin american Spanish, lexicon, Yucatan Spanish, 18th. century, americanism.

\section{INTRODUCCIÓN: LA DESCONOCIDA HISTORIA DEL ESPAÑOL DE YUCATÁN}

Son numerosas las razones que convierten el español de Yucatán en una variedad lingüística de primer interés y en cierto modo especial dentro del mapa dialectal del mundo hispánico: aunque muchas de ellas son sobradamente conocidas, no está de más señalar algunas como, por ejemplo, su clara especificidad dentro de las variedades lingüísticas de México - a este respecto, indica el mismo Lope Blanch (1987: 7) que "el español yucateco se distingue vigorosa y nítidamente de las restantes modalidades lingüísticas del país"-, la influencia clarísima de la lengua maya, que "abarca todos los niveles de la lengua: el lexicológico, el morfosintáctico y el fonético" (Lope Blanch, 1987: 9), o, desde una perspectiva dialectal más amplia, el hecho — prácticamente único- de que una variedad costera presente un consonantismo fuerte, propio de las zonas altas interiores (Alvar, 1990: 178) ${ }^{1}$; súmese a esto, además, diferentes cuestiones de carácter histórico que aportan también cierto grado de originalidad al territorio, tales como su temprana conquista — que contrasta, sin embargo, con la tardía consolidación y generalización del español en la región- o el aislamiento administrativo y la notable distancia geográfica que existe respecto al centro del virreinato novohispano, todo lo cual termina por configurar la península de Yucatán como una zona muy peculiar desde muchos puntos de vista, también en lo que a su variedad de español se refiere.

Precisamente por todo ello, no deja de sorprender que el aserto de Lope Blanch (1987: 5) de que "el español yucateco no ha sido todavía suficientemente estudiado" siga a día de hoy, más de veinticinco años después, manteniendo su plena vigencia: en efecto, a pesar del tiempo transcurrido y de las investigaciones llevadas a cabo hasta el momento - desde las pioneras de Bolio Ontiveros (1931), Patrón Peniche (1932), Heredia (1934), Barrera Vázquez (1937) y Suárez (1945) hasta las más recientes de Yager (1989), Pfeiler (1995), Espejo (1999) o Michnowicz (2009, 2011), pasando por García Fajardo (1984), Alvar (1990) y, por supuesto, por los trabajos del mismo Lope Blanch

\footnotetext{
${ }^{1}$ Algo que Rosenblat (1967: 136) justifica porque la Península "aunque es en general tierra baja, constituye una prolongación de la cultura maya de las tierras altas de Guatemala", si bien son muchos los interrogantes - muy especialmente históricos - que al respecto hay que responder antes de dar por válida esta hipótesis.
} 
(1987, 1990) — sigue siendo "mucho, muchísimo más lo que falta por hacer" (Lope Blanch, 1987: 5), hasta tal punto que no es exagerado decir que la región constituye, desde muchos puntos de vista, una de las menos estudiadas del continente.

No sorprende, por tanto, que lo que en sincronía es "pobreza de la bibliografía relativa al español yucateco" (Lope Blanch, 1987: 5), en el caso de la diacronía sea prácticamente inexistencia total, con la excepción de los trabajos desarrollados hasta el momento por Ramírez Quintana (2008, 2009, 2011), dedicados a la tarea fundamental de compilar un corpus documental en el que llevar a cabo posibles estudios de épocas pasadas y a la presencia de mayismos en tales documentos, o por Mora Peralta (2008), donde se analiza la onomástica maya también desde una perspectiva histórica; trabajos relevantes para la historia del español en la región, pero que evidencian al mismo tiempo la escasez de datos con la que cuenta por el momento el investigador interesado en la historia lingüística de Yucatán, y que demuestran, así mismo, la necesidad de llevar a cabo más estudios que, poco a poco, vayan completando la visión muy parcial que por el momento se tiene de la evolución histórica de la lengua española en la Península.

Antes de continuar, conviene señalar la estructura que se va a seguir en el artículo, que es la siguiente: tras esta breve introducción (sección 1), se procederá a señalar los objetivos fundamentales que persigue el trabajo y el corpus en el que se basa (sección 2), para pasar a continuación a analizar el concepto de americanismo (sección 3), de primera importancia en un análisis como el que se pretende desarrollar a lo largo de estas páginas; posteriormente se llevará a cabo el estudio de las voces que, a partir de lo señalado en el punto anterior, se engloban dentro de este concepto (sección 4), para lo cual se atenderá a cuestiones muy diversas como los subtipos de americanismos presentes en la documentación (sección 4.1.), las voces de origen indígena que aparecen (sección 4.2.) o la configuración léxica del español yucateco durante los siglos XVII y XVIII (sección 4.3.). Por último, el artículo concluye con un apartado final (sección 5) donde se exponen las principales conclusiones a las que se ha llegado en el análisis, así como nuevas tareas que, a partir de estas páginas, parece necesario atender en posteriores trabajos.

\section{OBJETIVOS DEL ESTUDIO Y CORPUS ANALIZADO}

Teniendo en cuenta la situación descrita, el presente trabajo pretende aportar algunos datos que sirvan para ir completando la visión parcial a la que se ha hecho mención anteriormente. Así, se procurará llevar a cabo un análisis del 
léxico empleado en la zona entre 1650 y $1800^{2}$, en concreto de todos aquellos elementos que, por diversos motivos - y desde diferentes puntos de vista- se pueden calificar como americanismos, con el propósito de analizar la configuración léxica del español yucateco en el periodo seleccionado y aportar una primera descripción del vocabulario que se emplea en la región en esos momentos.

De este modo, los propósitos concretos que se persiguen en este trabajo son los siguientes: 1) discutir el concepto de americanismo y establecer una definición satisfactoria que permita dar cuenta del léxico que, desde diferentes puntos de vista, caracteriza el español americano y, en este caso concreto, yucateco; 2) aislar las diversas unidades léxicas que, de acuerdo con la concepción del americanismo que se emplea en este estudio, se pueden englobar en tal categoría; 3) estudiar la presencia cuantitativa de los distintos tipos de americanismos, así como su distribución en campos léxicos; 4) analizar - como categoría solo parcialmente coincidente con la anterior - los indigenismos presentes en el corpus, sus orígenes y su distribución en campos léxicos; y 5) explorar los porcentajes de las diversas estrategias de americanización del vocabulario (indigenismos vs. americanismos endohispánicos), con el propósito de describir, según se ha advertido ya, la posible configuración léxica del español de la zona ${ }^{3}$.

Con este propósito, se ha seleccionado como corpus base de análisis el conjunto de documentos presentes en Melis y Rivero Franyutti (2008), que cumplen dos requisitos fundamentales: a) corresponder desde el punto de vista geográfico a la Península del Yucatán (actualmente, estados de Yucatán y Campeche ${ }^{4}$;

${ }^{2}$ Las fechas que abarca este estudio no se han elegido al azar, sino que guardan relación con la situación que constata para el centro de la Nueva España Company (2007: 86), quien señala que "las últimas décadas del siglo XVII y las primeras del siglo XVIII son, a mi entender, el momento central en el que la idiosincrasia lingüística de México tomó carta de naturaleza en la vida cotidiana de los hombres y mujeres comunes novohispanos". Se pretende, por tanto, comprobar si algo semejante —en este caso, en el nivel léxico — se produce en el caso concreto de Yucatán, esto es, si existe ya una especificidad propiamente yucateca en este nivel lingüístico.

3 Aunque se insistirá en ello más adelante, se entiende aquí por configuración léxica el empleo preponderante de determinadas estrategias en el proceso de dialectalización del léxico —en este caso, naturalmente, americanización-, que conlleva como resultado final "un mapa léxico propio que va a identificar a una región por medio de un conjunto de voces que, sean conocidas solamente en la zona o tengan un significado especial en ese lugar, constituyen un rasgo de identidad que distingue esa variedad del español de todas las demás del mundo hispánico" (Ramírez Luengo, 2012: 395); véase este trabajo, así como Gómez González (2013), para la aplicación de tal concepto al caso concreto de la Bolivia de los siglos XVIII y XIX.

${ }^{4}$ A pesar de que en ocasiones se haya discutido la pertenencia dialectal de Campeche al habla yucateca, señala Lope Blanch (1990: 59) que "desde el punto de vista léxico, la zona de Campeche e inclusive, en algunos casos, la costa sur de Tabasco están más cerca de la norma lingüística yucateca que de la veracruzana", por lo que "cabe pensar que el habla de Campeche pertenece dialectalmente al habla yucateca, aunque tal vez posea ciertas peculiaridades distintivas que permitan considerarla como una variedad del dialecto yucateco" (Lope Blanch, 1990: 121). 
y b) estar datados entre las fechas límites ya indicadas ${ }^{5}$. El resultado de aplicar tales criterios diatópico-diacrónicos es un conjunto de 41 documentos de longitud variable datados en diversos lugares de los estados señalados, muy especialmente en sus capitales - Campeche y Mérida-, pero también en otras poblaciones como Cauich, Maní, Teabo o Valladolid ${ }^{6}$.

Por otro lado, conviene señalar que, desde el punto de vista de la tipología, los documentos se engloban en su gran mayoría en lo que se ha dado por llamar el universo de los discursos jurídico-administrativos, con ejemplos de informes (docs. 114, 149), denuncias (docs. 99, 176), testimonios (docs. 117, 173) o peticiones (doc. 125), si bien tampoco faltan entre ellos algunos textos epistolares dirigidos a familiares, particulares o autoridades (entre otros, docs. 171,180 y 174, respectivamente). Se trata, por tanto, de un corpus enormemente diverso en lo que a los tipos textuales se refiere, lo que determina que los contenidos sobre los que versa la documentación sean también notablemente variados. Ello redunda, como se indica en Ramírez Luengo (2011), en una presencia igualmente variada de vocabulario perteneciente a ámbitos de muy distinto tipo, lo que no hace sino evidenciar la importancia que posee la documentación de archivo en general - y la seleccionada por los autores de la presente antología para el caso concreto de Yucatán- para el estudio histórico del léxico americano.

\section{UN CONCEPTO FUNDAMENTAL: EL AMERICANISMO}

En un estudio que tiene por objetivo fundamental analizar la presencia de americanismos léxicos en el español yucateco de los siglos XVII y XVIII, resulta imprescindible en primer lugar aportar una definición de tal concepto que sirva de marco teórico en la búsqueda de tales elementos diferenciales. A este respecto, cabe señalar que las formas de entender el americanismo son múltiples y muy dispares ${ }^{7}$, de manera que en esta ocasión - y siguiendo, de este modo, el

\footnotetext{
${ }^{5}$ Conviene indicar que no se han considerado otros (posibles) criterios de discriminación, como, por ejemplo, la tipología textual —en este sentido, se ha aceptado cualquier tipo de documento, si bien la práctica totalidad de ellos pertenecen a lo notarial, entendido de una forma muy amplia- o el origen étnico del autor del texto, al tomarse en cuenta los redactados por autores criollos (docs. 74, 83, 153) e indígenas (docs. 149, 150).

${ }^{6}$ En concreto, los documentos seleccionados — de acuerdo con la numeración de los autores (Melis y Rivero Franyutti, 2008) — son los siguientes: para Campeche, docs. 79, 81, 90, 106, 123, 124, 140, 141 y 153; para Yucatán, docs. 80, 82, 83, 84, 99, 100, 105, 107, 109, 114, 117, $118,121,125,130,134,135,137,138,139,149,150,169,170,171,172,173,174,175,176$, 180 y 181

${ }^{7}$ A veces incluso opuestas, como demuestra la excelente revisión historiográfica de este concepto que lleva a cabo Donadío Copello (2005: 89-92).
} 
ejemplo de trabajos previos (Ramírez Luengo, 2011, 2012, en prensa, en prensa b) - se ha optado por utilizar una interpretación de este concepto que se basa en la que Company (2007: 28-29) facilita del mexicanismo. De esta manera, el americanismo lingüístico se define como 'el conjunto de voces, formas o construcciones que son caracterizadoras del habla urbana, popular o culta, o ambas, de América y cuyo uso muy frecuente y cotidiano distancia la variedad americana respecto del español peninsular' y los americanismos serán, naturalmente, cada uno de los elementos aislados que constituyen la unidad enunciada.

Salta a la vista que una definición como la apuntada en estas líneas resulta especialmente útil en un estudio histórico de los americanismos por determinados aspectos que en sí misma presupone, y de los que se derivan principios metodológicos de gran importancia para un análisis riguroso de estos elementos. En concreto, tales aspectos fundamentales son los siguientes: a) la consideración del uso como criterio único para el establecimiento de los americanismos; b) el carácter eminente y básicamente histórico de esta categoría; y c) la existencia de diversas formas de cumplir la definición anterior o, si se quiere, de diversos tipos de americanismos, que la misma Company (2010: XVII) denomina puros 'voces empleadas en el español general de América inexistentes en el español peninsular general', de frecuencia 'voces o construcciones compartidos, en forma y significado, con el español peninsular castellano, pero que muestran en América una mucho mayor frecuencia de empleo y de generalización' y semánticos 'voces y construcciones formalmente compartidas con el español peninsular, pero que han desarrollado en América valores semánticos propios'.

Por supuesto, salta a la vista que la interpretación del americanismo, de acuerdo con estas premisas, implica no pocos problemas a la hora de intentar llevar a cabo de forma rigurosa su estudio histórico, muy especialmente en lo que tiene que ver con los puntos a) y b) ${ }^{8}$. En realidad, tanto estos dos aspectos

\footnotetext{
${ }^{8}$ Aunque tampoco está exento de dificultades el punto c), relacionado con los tipos de americanismos que se pueden englobar en ese concepto, pues en ocasiones no es nada sencillo ubicar determinadas voces dentro de alguna de las categorías que se establecen — con claridad meridiana, dicho sea de paso- de forma teórica. A manera de ejemplo, en este trabajo se ha optado por considerar botar como americanismo de frecuencia, por su aparición más habitual en textos americanos en la época analizada, de acuerdo con los datos de CORDE (consulta: 09/07/2014); sin embargo, el hecho de que existan diferencias de matiz en el empleo de esta voz entre España y América — según Hildebrandt (1961: 282-283), botar connota cierta violencia en España que no presenta en América- y que tal diferenciación, según apunta Autoridades (DECH, 1980-91: s. v. botar), se pueda retrotraer a pleno siglo XVIII obliga a plantearse si no se debería considerar más bien un americanismo semántico, o al menos parcialmente semántico, con todas las dificultades que tal cuestión puede conllevar. Esta misma contradicción entre las fuentes se descubre también en el término encomendero: americanismo semántico según los datos del DRAE (2001: $s$. v. encomendero), Autoridades (RAE, 1979: s. v. encomendero) indica que "es término mui usado entre los Comerciantes de Indias" para su primer significación y relaciona directamente con este
} 
como la definición en sí misma parten de la valoración de la extensión léxica ${ }^{9}$ que los determinados elementos presentan en una época concreta, y si conocer tal extensión resulta ya de por sí complicado para el momento actual ${ }^{10}$, los problemas se multiplican en el caso de sincronías pasadas, habida cuenta de los vacíos en la información —diatópica, pero también diastrática y diafásica, fundamental para valorar algunos de estos elementos- a los que se enfrenta el investigador y las limitaciones que indefectiblemente imponen los corpus de los que este dispone en el momento actual ${ }^{11}$.

Esta situación inmediatamente descrita se hace evidente, por ejemplo, a la hora de estudiar el léxico presente en el corpus que constituye la base del presente trabajo: en efecto, aunque en ocasiones la falta de información es paliada por el mismo contexto de aparición del vocablo considerado, donde se explicita su carácter local - y a este respecto, resultan paradigmáticos los casos de guano 'tipo de palma' o chorreado 'tipo de chocolate' (ejemplos 1 y 2)-, lo cierto es que los escasos (o directamente nulos) datos que, por ejemplo, ofrecen para

continente la segunda, lo que parece hablar de un empleo más general en el Nuevo Mundo y, por tanto, de su carácter de americanismo de frecuencia; como en otras ocasiones, también aquí se ha optado por utilizar los datos que facilita CORDE para su clasificación, y es precisamente esta decisión la que obliga a considerar este elemento en el siglo XVIII — no sin ciertas dudas- como americanismo semántico.

${ }^{9}$ Aunque en numerosas ocasiones se entiende la extensión léxica como la adquisición de nuevas significaciones por parte de un término concreto (una extensión, pues, de tipo semántico), en esta oportunidad el concepto se relaciona eminentemente con lo espacial y se define como todo proceso (histórico) de modificación en la distribución geográfica de una voz, sea de expansión (generalización) o de reducción (dialectalización)'; por supuesto, esta extensión léxica puede afectar tanto a la voz en sí como únicamente a alguna de sus significaciones.

${ }^{10}$ Tiene razón, pues, Frago (2010: 198) al indicar que "no siempre resulta fácil (...) determinar la completa difusión de una palabra en el español americano, y quizá más problemático resulta delimitar las zonas de los regionalismos, comúnmente de gran extensión y a veces localizados en áreas discontinuas, en no pocas ocasiones también con distintas acepciones, dificultad dialectológica a la que contribuyen las deficiencias que en información lexicográfica actual todavía subsisten". Muestra (en principio) evidente del aserto del profesor zaragozano es que el DAM (2010) no registre como mexicanas —o centroamericanas, dada la relación de Yucatán con esta región - voces presentes en la documentación aquí estudiada como aloja, cacique, embarro, estancia, ingenio, largar, moreno, pardo, ramada y zafar, así como que Morínigo (1998) muestre una situación semejante en el caso de aloja, cascarilla, chino, contesto, estancia, guano, isleño, limeta, pardo y tamarindo. Existe la posibilidad, con todo, de que su ausencia en los diccionarios sincrónicos no sea muestra de las deficiencias señaladas por Frago, sino más bien de los procesos que se han englobado anteriormente dentro del concepto de extensión léxica, que puede haber determinado la desaparición de tales voces del español yucateco en algún momento histórico situado, obviamente, entre el siglo XVIII y la actualidad.

${ }^{11}$ Afortunadamente, se anuncia la pronta aparición de nuevos corpus informatizados de gran envergadura -en concreto, CHARTA, dirigido por Pedro Sánchez-Prieto, de la Universidad de Alcalá (España), y CORDIAM, coordinado por Concepción Company, de la UNAM (México), y Virginia Bertolotti, de la Universidad de la República (Uruguay)—, lo que probablemente pueda contribuir a solucionar parte de las dificultades mencionadas. 
foguerada, limeta o taurete tanto los grandes corpus informatizados - especialmente, los repositorios de la Real Academia, CORDE, CREA y $C D H-$ como los distintos repertorios lexicográficos, así como las frecuentes inconsistencias que se registran entre estos últimos, dificulta en mucho el conocimiento de su extensión léxica y, por tanto, su valoración o no como americanismos ${ }^{12}$ :

1. Una pequeña casa pajiza o, como aquí llaman, de guano (Doc. 99; Mérida, 1691 $)^{13}$.

2. Lo primero es hacerles chocolate todos los días, que llaman en esta tierra chorreado, que es chocolate de pobres, y el desayuno indispensable, que no hay otro desayuno (Doc. 106; Campeche, 1702).

Por otro lado, es evidente que el uso de un determinado vocablo no tiene por qué mantenerse diatópicamente estable a lo largo del tiempo, sino que, muy al contrario, resulta frecuente en la historia del español que se registren casos del fenómeno que se ha denominado extensión léxica, que conlleva el empleo de tal vocablo en zonas geográficas donde anteriormente era desconocido. Así pues, si se tiene en cuenta que, según se ha dicho ya, la valoración de un término como americanismo deriva exclusivamente de su ámbito de empleo y que tales ámbitos de empleo se pueden ver modificados históricamente como resultado de las ya mencionadas extensiones léxicas, parece necesario sostener el carácter dinámico del concepto americanismo, o, si se quiere, que "la valoración de determinado elemento como americanismo no se mantiene inalterada a través del tiempo, sino que puede variar a lo largo de la historia, dependiendo de los procesos de expansión o reducción geográfica que experimenten las diferentes unidades léxicas" (Ramírez Luengo, 2012: 398).

\footnotetext{
${ }^{12}$ En concreto, foguerada no aparece en ninguno de los tres repositorios - CORDE, $C D H$ o CREA - así como tampoco en el DAM (2010) ni en el DRAE (2001); es posible que se trate de uno más de los muchos occidentalismos del español de América, habida cuenta de la existencia de la forma fogueirada 'hoguera externa y que produce mucha llamarada' (Alonso, 1958: s. v. fogueirada) en Asturias y Galicia, y de formas como foguerear 'quemar un campo o monte; hacer una hoguera' (Morínigo, 1998: s. v. foguerear) en Cuba o Chile. Por su parte, limeta 'tipo de botella' se registra hoy como americanismo presente en Paraguay (Morínigo, 1998: s. v. limeta), el sureste mexicano (DAM, 2010: s. v. limetón) o zonas diversas como Chile, Cuba y el Río de la Plata ( $D E C H$, 1980-91: s. v. limeta), si bien en el DRAE (2001: s. v. limeta) aparece sin indicación geográfica de ningún tipo y los —escasísimos - datos de CORDE, CDH y CREA impiden conocer con cierta fiabilidad su distribución histórica y actual. Por último, taurete 'taburete' resulta voz propia de Nicaragua según el DRAE (2001: s. v. taurete), pero su aparición tanto en Autoridades (RAE, 1979: s. v. taurete) como en Terreros (1987 [1786-88]: s. v. taurete) obliga a interrogarse —en relación con el carácter dinámico del concepto americanismo, del que se hablará a continuación - si ya en el siglo XVIII su uso era propiamente americano o aún constituía, por el contrario, una voz general en el español; una vez más, la práctica inexistencia de datos en los repositorios académicos impide determinar la distribución geográfica de la voz, tanto histórica como actualmente.

${ }^{13}$ Habida cuenta de que el interés de este trabajo es meramente léxico, se opta por modernizar la grafía y la acentuación de los fragmentos documentales seleccionados.
} 
Al igual que ocurría en estudios previos sobre otras zonas americanas (Ramírez Luengo, en prensa), el corpus aquí analizado demuestra una vez más lo acertada que resulta la concepción dinámica de este concepto, así como la necesidad que existe de incorporarla a los análisis si lo que se pretende es llevar a cabo un estudio profundo y riguroso de la historia del léxico del español americano y de la configuración de su especificidad regional. A manera de ejemplo, si bien es indudable que acabalar constituye a día de hoy un americanismo — probablemente puro, a juzgar por los ejemplos presentes en CREA-, y así lo interpreta alguna obra lexicográfica $(A M L, 2010: s$. v. acabalar), su aparición en Autoridades (RAE, 1979: s. v. acabalar) y Terreros (1987 [1786-1788]: s. v. acabalar) sin nota de ningún tipo y su registro en autores españoles de la época áurea $(D E C H, 1980-1991: \text { s. v. acabalar })^{14}$ sugieren su carácter más o menos general en el español de la época y, por tanto, su no pertenencia en este momento a la nómina de americanismos ${ }^{15}$. Del mismo modo, los datos de CREA obligan a considerar como actuales americanismos de frecuencia las voces $c a$ samiento, colorado, enojado o quebrar ${ }^{16}$, pero lo cierto es que el análisis histórico del empleo de estos vocablos en los siglos XVII y XVIII - a partir de los datos de CORDE - demuestra que tales voces resultaban generales en la época, por lo que tampoco se pueden considerar americanismos en la sincronía que se está analizando en estas páginas ${ }^{17}$.

Salta a la vista, por consiguiente, que un estudio profundo del léxico americano de épocas pasadas indefectiblemente precisa tener en cuenta el dinamismo de un concepto como el de americanismo y por ello resulta necesario juz-

14 Desgraciadamente, la escasez de apariciones dieciochescas en CORDE — tres casos en el intervalo 1650-1700; cuatro para todo el siglo XVIII - impide, una vez más, utilizar este repositorio para el análisis de la distribución de la voz en las diversas zonas geográficas del mundo hispánico en la época.

15 Se trataría de un ejemplo más de los innumerables arcaísmos americanos o pseudoarcaísmos que Moreno de Alba (2007: 190) señala en el español de América, esto es, voces que constituyen americanismos desde el punto de vista sincrónico y arcaísmos si se contemplan en su devenir histórico.

${ }^{16}$ El mismo DECH (1980-91: s. v. colorado, enojado, quebrar) resalta en el caso de las tres últimas su pervivencia y vitalidad en las hablas americanas, frente a la decadencia que han experimentado en el español peninsular.

17 En concreto, los datos de CORDE (consulta: 09/07/2014) para el siglo XVIII son los siguientes: casamiento, 321 casos en España frente a 66 en América (83\%-17\%); colorado, 462 casos en España frente a 375 en América (55\%-45\%); enojado, 209 casos en España frente a 81 en América (72\%-28\%); quebrar (solo formas no personales del verbo), 123 casos en España frente a 65 en América (65\%-35\%). Ni que decir tiene que es necesario interpretar estos números únicamente como muestra — probablemente difusa y no del todo rigurosa - de las tendencias de uso de estas unidades léxicas en el Siglo de las Luces, pues no se debe olvidar que las propias características de CORDE — con un claro desequilibrio cuantitativo en sus fondos a favor de España- complican o incluso imposibilitan un análisis más profundo, según se explica detalladamente en Ramírez Luengo (en prensa). 
gar el carácter diferencial/regional de los diversos vocablos desde la sincronía que se está analizando, pues en caso contrario es relativamente fácil ofrecer una descripción distorsionada de la especificidad léxica del español americano de determinado momento y se corre el riesgo de ofrecer una visión anacrónica y poco ajustada a la realidad de los procesos de dialectalización que este nivel lingüístico experimenta en América a lo largo de su historia.

\section{LOS AMERICANISMOS EN EL ESPAÑOL YUCATECO DE LOS SIGLOS XVII Y XVIII}

De este modo, el expurgo pormenorizado de los documentos que constituyen el corpus del presente estudio arroja un total de 49 términos que se pueden considerar americanismos en la sincronía que se está analizando, esto es, que cumplen con la definición de este concepto que se ha facilitado en el epígrafe anterior y que, además, parecen presentar tal carácter ya en los siglos XVII y XVIII de acuerdo con su ámbito geográfico de uso y su frecuencia de empleo ${ }^{18}$; en concreto, el conjunto de vocablos es el siguiente: aloja, balché, banda 'lado', barbacoa, batea, botar, cascarilla, ceiba, ceibana, chicha, chino como apelativo cariñoso, chorreado 'tipo de chocolate', cimarrón, contesto, copal, curato, doctrinero, embarro, embrocar, encomendero, enguanar, estancia, frijol, guano 'tipo de palma', hamaca, indio, ingenio 'lugar donde se procesa el azúcar', isleño 'canario' ${ }^{19}$, jícara, ladino, largar 'tirar, arrojar', milpa, milpero, moreno 'per-

\footnotetext{
${ }^{18} \mathrm{El}$ establecimiento de qué elementos entran dentro de la categoría de americanismo se ha llevado a cabo a partir de los datos que ofrece CORDE para la sincronía estudiada (1650-1800). Desde un punto de vista metodológico, se ha interpretado americanismo puro aquella voz que solo se descubre en América o en textos clasificados por CORDE como españoles pero de temática americana - al estilo de la Historia de la Conquista de la Provincia del Itzá (1701), de Juan de Villagutierre Sotomayor-; americanismo semántico el que ofrece en los ejemplos del corpus un significado que coincide con el actual americano — según el DAM (2010), pero también Morínigo (1998) y el Diccionario de mexicanismos (AML, 2010), en menor medida el DRAE (2001) - y difiere del que le asignan al vocablo en cuestión diversas obras lexicográficas del siglo XVIII, en especial Autoridades (RAE, 1979) y Terreros (1987 [1786-1788]); y por último americanismo de frecuencia el que, en la sincronía ya indicada, presenta en CORDE un número mayor de ejemplos americanos que españoles. Con todo, se trata de soluciones provisionales que solo permiten un acercamiento parcial y manifiestamente mejorable a esta cuestión, y que será necesario ir afinando con el tiempo, muy especialmente en lo que tiene que ver con los americanismos de frecuencia.

${ }^{19}$ Como bien señala Hildebrandt (1961: 302), "los isleños eran, por antonomasia, los naturales de las Islas Canarias", hasta el punto de que el vocablo se puede considerar, en la América de los siglos XVIII y XIX al menos, casi como un gentilicio para los canarios; en el caso concreto de la documentación yucateca, los propios editores (Melis y Rivero Fanyutti, 2008: 398) indican que en un fragmento no transcrito del mismo texto se habla de "algunos religiossos de varias religiones, venidos de las yslas Canarias", lo que certifica el significado de 'canario' que la voz presenta en el corpus.
} 
sona de raza negra', motón, pardo 'persona de raza negra', patí, petaca, pierna 'medida de longitud', piragua, pozole, ramada, ranchería, sacá, soguilla ${ }^{20}$, tamarindo, tilma, zacate, zafar ${ }^{21}$.

\subsection{Tipos de americanismos}

Por supuesto, un acercamiento siquiera superficial demuestra que, tal y como se ha planteado anteriormente, no todas las voces cumplen de la misma manera la definición de americanismo facilitada más arriba, circunstancia que permite clasificar estos elementos dentro de los subtipos establecidos por Company (2010: XVII). De este modo - y teniendo en cuenta los datos de CORDE sobre su distribución geográfica en los siglos XVII y XVIII-, se registran 22 americanismos puros, otras 22 voces que se pueden considerar americanismos semánticos $\mathrm{y}$, de forma mucho más escasa, cinco términos englobables dentro de los americanismos de frecuencia. A partir de estos datos, es posible extraer una serie de observaciones de interés: en primer lugar - como no podía ser de otra forma-, la convivencia de los tres tipos de americanismos en el español yucateco de los siglos XVII y XVIII; en segundo lugar $-\mathrm{y}$ probablemente más importante-, se constata que no todos los tipos de americanismo tienen una presencia cuantitativamente semejante en esta variedad lingüística, pues mientras que existen dos grupos privilegiados — puros y semánticos, con un $45 \%$ del total cada uno-, los americanismos de frecuencia parecen ser mucho más escasos, al equivaler a un mero $10 \%$ de todas las voces, situación que, dicho sea de paso, no resulta exclusiva de esta variedad lingüística, sino que se descubre también en otras de esta misma época, como las del oriente y occidente de la actual Bolivia (Ramírez Luengo, 2012: 402; en prensa).

Por lo que se refiere a los americanos puros, los datos que CORDE facilita para los siglos XVII y XVIII han permitido interpretar de esta manera las siguientes voces: balché, barbacoa, ceiba, ceibana, chicha, chino, contesto, copal, embarro, enguanar, guano, hamaca, milpa, milpero, patí, petaca, piragua, pozole, ranchería, sacá, tilma, zacate. Salta a la vista la presencia mayoritaria de indigenismos entre estos elementos -16 de 22 , el $73 \%$ del total-, pero conviene señalar que también se registran elementos endohispánicos gene-

${ }^{20}$ Aunque los editores leen soquilla (doc. 134; Mérida, 1746), muy probablemente se trate del término soguilla 'collar, adorno que una mujer se pone en el cuello', registrado en Centroamérica por el DAM (2010: s. v. soguilla) y cuyo significado encaja perfectamente en el contexto de aparición: "Dixo que se le havía perdido una soquilla de perlas" (Doc. 134; Mérida, 1746).

${ }^{21}$ Teniendo en cuenta las dificultades planteadas en el apartado anterior, se ha optado por dejar fuera de la lista los términos cuya valoración como americanismo resulta dudosa o difícil de precisar, tales como los ya mencionados foguerada, limeta o taurete. 
ralmente derivados, al estilo de contesto, embarro o ranchería ${ }^{22}$. Así mismo, es también destacable la presencia de estos elementos en campos semánticos variados, tales como la flora (ceiba, copal, guano) o la alimentación (balché, chicha, pozole) -favorecedores del empleo de este tipo de voces, dadas las especificidades de la realidad y la vida americanas-, pero también en otros como los enseres y la vestimenta (hamaca, patí, petaca, tilma) o los apodos (ceibana, (hino) $)^{23}$.

En cuanto a los americanismos semánticos, el corpus registra también 22 elementos que se pueden incluir dentro de esta categoría por presentar, ya en este momento, una significación diferente a la que poseen en el español de España, y que en concreto son los siguientes: aloja, banda 'lado', batea, cascarilla, chorreado 'tipo de chocolate', cimarrón, doctrinero, embrocar, encomendero, estancia, ingenio 'lugar donde se procesa el azúcar', isleño 'canario', ladino, largar 'tirar, arrojar', moreno 'persona de raza negra', motón, pardo 'persona de raza negra', pierna 'medida de longitud', ramada, soguilla, tamarindo, zafar.

A semejanza de lo que ocurría con estos elementos en la Bolivia dieciochesca (Ramírez Luengo, en prensa), el análisis de los vocablos permite extraer dos conclusiones de cierto interés: por un lado, el hecho - lógico y deducible de la misma definición del americanismo semántico_ de que prácticamente todas las voces englobables en esta categoría pertenezcan al fondo léxico patrimonial del español ${ }^{24}$; por otro, que estos americanismos pertenezcan a campos semánticos muy diferentes, que hacen referencia a variadas realidades de la vida cotidiana, como pueden ser la alimentación (aloja, chorreado), la construcción (estancia, motón) o la organización social (encomendero, ladino, moreno), circunstancia que, desde un punto de vista histórico, "evidencia la rapidez con que la naciente sociedad colonial se asienta y aclimata al Nuevo Mundo" (Franco Figueroa, 1991: 225-226) y al mismo tiempo —y desde lo estrictamente lingüísticoconfirma la importancia que tiene este procedimiento de metaforización y modificación semántica en la configuración del léxico del español de América.

22 Se descubren también derivados según la morfología del español a partir de bases indígenas, al estilo de ceibana, milpero o enguanar; se trata, de esta forma, de unos elementos a mitad de camino entre las dos categorías mayoritarias señaladas, habida cuenta de que no son indigenismos, pero tampoco caben — al menos, cómodamente- dentro de la categoría de elementos endohispánicos.

${ }^{23}$ En este punto los datos contrastan poderosamente con los que ofrecen unas crónicas jesuíticas del oriente boliviano dieciochesco, en las que la presencia de americanismos puros en el ámbito de la flora y de la fauna era notablemente mayoritaria (Ramírez Luengo, en prensa). Este hecho evidencia la influencia fundamental que posee la tipología textual del corpus empleado en los resultados que se obtienen en la búsqueda de americanismos, algo que ya se señalaba en el trabajo citado y que será necesario tener en cuenta a la hora de establecer - o intentar establecer- la configuración léxica de la variedad dialectal en cuestión.

${ }^{24}$ La única excepción la constituye - y de forma discutible - el probable antillanismo batea. 
En esta línea de modificación significativa, y dentro aún del conjunto de voces que componen los americanismos semánticos, cabe destacar la aparición en el corpus de una serie de términos como banda, largar, motón o zafar que se pueden considerar marinerismos de tierra adentro (Frago, 2010: 59), esto es, voces en principio propias del ámbito marinero que por medio de los procesos de modificación semántica ya mencionados, pasan a referirse a realidades no marítimas (Ramírez Luengo, 2007: 81). Por supuesto, no se trata de un fenómeno propio o exclusivo de la variedad dialectal estudiada en estas páginas, sino más bien de muestras, en el español yucateco de los siglos XVII y XVIII, de una tendencia muy general en América, pues - como bien recuerda Frago (2010: 59) — las peculiares circunstancias de la colonización del Nuevo Mundo determinan que "en el español americano el léxico marinero arraigara extraordinariamente, convirtiendo sus anteriores registros, propios de un especial oficio, en usos populares, mediante un curioso cambio semántico" 25 .

Por último, se ha indicado ya que los americanismos de frecuencia son claramente minoritarios en el corpus, al equivaler únicamente a cinco elementos, es decir, a apenas un $10 \%$ del total de los vocablos; en concreto, se trata de los términos botar, curato, frijol, indio y jícara ${ }^{26}$. Más allá de su escasez, es im-

\footnotetext{
${ }^{25}$ Para el caso de banda y zafar, el DECH (1980-91: s. v. banda, zafar) deja bien a las claras su carácter de marinerismos al indicar para el primer caso que "en España es casi exclusivamente náutica, mientras que en América (...) se extiende hasta significar 'zona' y 'orilla, margen'”, y para el segundo que "en América, según ocurre con tantas voces náuticas, tiene empleo más amplio". En el caso de largar, el mismo diccionario indica que "es básica la acepción náutica, también documentada" (DECH, 1980-91: s. v. largar), algo que parece corroborar el DRAE (2001: s. v. largar) al afirmar que "úsase mucho en la marina". Además, sugieren CorominasPascual para estas tres voces —así como Frago (1999: 137, 142) para banda- el posible origen portugués (o al menos, el influjo de esta lengua) en su origen y evolución semántica, algo que tampoco sería de extrañar teniendo en cuenta la importancia de esta lengua en la configuración léxica del español americano. En cuanto a motón, las diversas obras lexicográficas donde este término aparece (DRAE, 1803: s. v. motón; DRAE, 2001: s. v. motón) lo registran exclusivamente con su significación marítima de 'garrucha de diversas formas y tamaños por donde pasan los cabos'; sin embargo, salta a la vista que no es este el significado que presenta en el corpus estudiado, sino más bien uno claramente relacionado pero de carácter no marinero, que evidencia, por tanto, el proceso de metaforización del que se ha hablado ya con anterioridad: "Lo prendió en un motón que estava en una pared en que se cuelgan hamacas" (Doc. 80; Mérida, 1660).

${ }^{26}$ Los datos que ofrece CORDE para el periodo que se está estudiando son los siguientes: botar (solo formas no personales del verbo), seis casos en España frente a once en América; $c u$ rato, 53 casos en España frente a 578 en América; jícara, 20 casos en España frente a 23 en América. Para el occidentalismo frijol, si bien CORDE no ofrece ningún ejemplo español de la época —-frente a 69 americanos_- el hecho de que Frago (1999: 18, 57) lo localice en leoneses y extremeños del siglo XVI y su propio uso actual permiten asegurar su empleo en los siglos XVII y XVIII en España, y de hecho la ausencia de casos peninsulares en el repositorio académico parece ser un argumento más a favor de la idea de una utilización mucho más general de este elemento en América. Por último, indio presenta el problema - ya planteado, siquiera superficialmente, en Ramírez Luengo (en prensa b) — de aquellas voces cuyo mayor empleo en América se
} 
portante destacar otras dos cuestiones acerca de este tipo de americanismo: por un lado, que en su seno se descubren mayoritariamente voces del fondo patrimonial hispánico (botar, curato, frijol, indio), pero también indigenismos (jíca$r a)$, algo que pone de manifiesto la ampliación del ámbito de empleo de estos elementos — previamente circunscrito, naturalmente, a las variedades americanas de la lengua - por medio de un proceso de extensión léxica que por fuerza debió de tener lugar en momentos previos y que está aún sin estudiar; por otro, que, al igual que en el caso de los dos subgrupos anteriormente estudiados, estos americanismos no se concentran exclusivamente en un campo semántico determinado, sino que aparecen en ámbitos de distinto tipo.

Por tanto, el estudio del vocabulario presente en este corpus muestra bien a las claras la variedad de términos que se pueden englobar dentro del concepto americanismo, pero también el interés y la productividad que, desde un punto de vista metodológico, ofrece este concepto cuando se define de la manera propuesta en estas páginas, no solo por facilitar una interpretación coherente que deja fuera las ambigüedades de otras definiciones, sino también por atender a los matices que singularizan las diferentes unidades que conforman el léxico diferencial del español de América y, por lo tanto, facilitar una forma eficaz de clasificarlo y analizarlo más profundamente.

Por otro lado - y aunque ya se ha tratado parcialmente la cuestión en los párrafos anteriores-, resulta interesante también analizar de forma general los campos semánticos en los que se pueden agrupar todos los americanismos del corpus, con el objeto de descubrir si existe alguna instancia o referente que se ve favorecido en estos procesos de americanización del léxico. De este modo, partiendo de la clasificación de los indigenismos de los siglos XVII y XVIII que establecen Mejías (1980: 22) y Polo Cano (2005: 189) respectivamente, los 49 americanismos que se registran en la documentación se pueden distribuir en las siguientes categorías ${ }^{27}$ :

debe principalmente a una mayor presencia del referente en la vida americana; dada esta situación, ¿hasta qué punto se pueden considerar estos elementos americanismos de frecuencia?, ¿y se deben interpretar de la misma forma que, por ejemplo, enojado o colorado, donde el uso predominante de las voces tiene que ver con elecciones de carácter normativo - entendido este concepto a la manera de la norma normal de Coseriu- y no tanto con la realidad extralingǘstica?

${ }^{27}$ A pesar de las objeciones que se pueden plantear a esta clasificación —debidas, principalmente, a los fuertes solapamientos que se producen entre algunas de sus categorías-, se ha optado en esta ocasión por seguirla por las posibilidades que ofrece para llevar a cabo una comparación entre los datos de este trabajo y los de otros momentos y zonas del continente americano. 


\begin{tabular}{|l|r|l|}
\hline \multicolumn{1}{|c|}{ CAMPO SEMÁNTICO } & \multicolumn{1}{|c|}{ CASOS } & \multicolumn{1}{|c|}{ VOCES } \\
\hline Organización social & $8(16 \%)$ & $\begin{array}{l}\text { cimarrón, curato, doctrinero, encomendero, } \\
\text { indio, ladino, moreno, pardo }\end{array}$ \\
\hline Industria / construcción & $7(14 \%)$ & $\begin{array}{l}\text { embarro, enguanar, estancia, ingenio, } \\
\text { motón, ramada, ranchería }\end{array}$ \\
\hline Alimentación & $6(12 \%)$ & $\begin{array}{l}\text { aloja, balché, chicha, chorreado, pozole, } \\
\text { sacá }\end{array}$ \\
\hline Flora & $5(10 \%)$ & cascarilla, ceiba, copal, guano, tamarindo \\
\hline Enseres / utensilios & $5(10 \%)$ & batea, barbacoa, hamaca, jícara, petaca \\
\hline Agricultura & $4(8 \%)$ & frijol, milpa, milpero, zacate \\
\hline Vestimenta & $3(6 \%)$ & patí, soguilla, tilma \\
\hline Apelativos & $3(6 \%)$ & ceibana, chino, isleño \\
\hline Medidas / monedas & $1(2 \%)$ & pierna \\
\hline Transportes & $1(2 \%)$ & piragua \\
\hline Clima / geografía & $1(2 \%)$ & banda \\
\hline Otros & $5(10 \%)$ & botar, contesto, embrocar, largar, zafar \\
\hline TOTAL & $49(100 \%)$ & \\
\hline
\end{tabular}

TABLA 1.—Distribución de los americanismos en campos semánticos.

Así pues, los datos inmediatamente expuestos demuestran que son campos semánticos como la organización social o la construcción — con ocho y siete elementos, respectivamente - los que acaparan la mayor parte de los americanismos del corpus, y no tanto otros que se pueden suponer más favorables a la presencia de estos elementos, tales como la flora, la agricultura, el clima y la geografía o la fauna, que ni siquiera está representado. A la vista de tales resultados, conviene indicar que tal estado de cosas de ningún modo se debe interpretar como reflejo de la situación que, en lo que tiene que ver con los americanismos, probablemente ofrece el español yucateco de la época, sino más bien como una consecuencia de la propia documentación que compone el corpus, lo que demuestra una vez más la capital importancia que tiene la tipología textual en los trabajos sobre la historia del léxico americano, así como la necesidad que se presenta a los estudiosos de tener en cuenta tal circunstancia a la hora de interpretar sus resultados ${ }^{28}$.

Con todo, quizá la conclusión más interesante que ofrece este análisis por campo semántico sea, precisamente, la misma multiplicidad de campos en los

${ }^{28}$ Así mismo, este hecho pone de manifiesto una necesidad más: la de reflexionar acerca de la misma constitutio corporis y de las características lingüísticas que identifican a los materiales que componen los diversos corpus de trabajo, cuestiones que muy probablemente han quedado relegadas en los estudios acerca de la historia del léxico del español del Nuevo Mundo. 
que se registran los americanismos del español yucateco, lo que, una vez más, evidencia bien a las claras cómo la americanización del léxico no solo afecta a las realidades más características e idiosincrásicas del Nuevo Mundo, como puede ser la flora, sino que en realidad tal fenómeno se produce en prácticamente todos los aspectos de la vida, y supone, por tanto, una auténtica reorganización de todo el sistema léxico del español que llega a tierras americanas.

\subsection{Voces de origen indígena}

Desde otro punto de vista, resulta también interesante analizar los indigenismos que aparecen en los textos — tengan carácter de americanismo o lo hayan perdido ya en este momento-, por constituir la prueba más evidente del contacto interlingüístico que se produce en América y de las consecuencias que este hecho conlleva en el nivel léxico. En concreto, el corpus analizado ofrece un total de 21 indigenismos, que son los que se registran a continuación: balché, barbacoa, batea, cacique, ceiba, chicha, chino, chocolate, copal, guano, hamaca, jícara, maíz, milpa, patí, petaca, piragua, pozole, sacá, tilma y zacate ${ }^{29}$.

A la luz de la lista anterior y de los datos que, una vez más, aporta CORDE para el periodo 1650-1800, es especialmente reseñable, en primer lugar, la gran cantidad de los elementos indicados —en concreto, 18 de 21, el 86\% de ellosque mantienen aún en el siglo XVIII su carácter de americanismo. En efecto, con la excepción de cacique, chocolate y maíz — bien conocidos en la España de la época y ampliamente utilizados en textos de muy diverso tipo ${ }^{30}$-, los vocablos que aparecen en la lista anterior son en su práctica totalidad de uso exclusivo en América (americanismos puros, por tanto), generalización de la que escapa jícara, que — como se indicó más arriba — probablemente constituye en estos momentos un americanismo de frecuencia. A partir de esta constatación, es posible extraer dos conclusiones: la primera $-\mathrm{y}$ de modo alguno sorprendente, cabe señalar - es la estrecha relación que existe entre el indigenismo y el americanismo puro, que equivale al $81 \%$ del total de estos elementos; la segunda tiene que ver con los procesos de extensión léxica de los que se ha hablado ya, pues el empleo habitual de voces como barbacoa, petaca y hamaca en el

29 Tanto para la determinación de las voces que tienen origen en las lenguas autóctonas americanas como para el establecimiento de ese mismo origen se han seguido las indicaciones del DECH (1980-1991) y el DAM (2010) fundamentalmente; de manera ocasional se atiende también a lo indicado por Morínigo (1998).

30 A manera de ejemplo, CORDE (consulta: 09/07/2014) localiza cacique en las Cartas Marruecas de Cadalso (1773-1774) y el Eusebio de Montengón (1786), chocolate en los Avisos de Barrionuevo (1654-1658) y en las Visiones y visitas de Torres Villarroel (1727-1728), y maíz en el Suplemento al Theatro Crítico de Feijoo (1740) o en un Informe de la Sociedad Económica de Madrid salido de la mano de Jovellanos (1794). 
español de la España actual y su valoración como americanismos puros en el siglo $\mathrm{XVIII}^{31}$ sugiere una generalización de tales vocablos por la península en momentos posteriores a la Centuria Ilustrada, esto es, en momentos muchos más tardíos de lo que —en principio — se podría considerar de forma intuitiva ${ }^{32}$.

Por otro lado, resulta también interesante analizar los orígenes etimológicos de los indigenismos que aparecen en el corpus, por cuanto este dato aporta información de cierta relevancia sobre la influencia que las distintas lenguas autóctonas tienen en el español de la región. De este modo, son el náhuatl y las lenguas antillanas ${ }^{33}$ — con ocho y siete voces respectivamente- las que de forma mayoritaria incorporan indigenismos al español yucateco de los siglos XVII y XVIII, mientras que el maya presenta una importancia mucho más relativa con aportes bastante más escasos: tres únicos elementos- y el resto de las lenguas (caribe, cuna, quechua) tienen una presencia meramente anecdótica, reducida a un único préstamo:

\begin{tabular}{|c|c|c|}
\hline LENGUA & CASOS & VOCES \\
\hline Náhuatl & $8(38 \%)$ & $\begin{array}{l}\text { chocolate, copal, jícara, milpa, petaca, } \\
\text { pozole }^{34} \text {, tilma, zacate }\end{array}$ \\
\hline Lenguas antillanas & $7(33 \%)$ & $\begin{array}{l}\text { barbacoa, batea, cacique, ceiba, guano, } \\
\text { hamaca, maíz }\end{array}$ \\
\hline
\end{tabular}

${ }^{31}$ De nuevo, a partir exclusivamente de los datos que ofrece CORDE (consulta: 09/07/2014), pues, por ejemplo, en el caso concreto de hamaca Andión (2004: 123-124) indica que "es un temprano indigenismo ya citado por Colón" y otros autores como Bernal Díaz, Castellanos, Oviedo y Pizarro entre otros; en todo caso, nótese que se trata en todas las ocasiones de autores españoles, pero relacionados de una u otra forma con América, lo que no aporta datos - o al menos, datos indiscutibles - acerca del empleo general de la voz en la España del siglo XVI.

32 Cabe señalar que resulta necesario analizar detenidamente los procesos de extensión léxica de los indigenismos — especialmente los antillanismos, pero no solo- por el español europeo, algo de lo que se han ocupado ya parcialmente Frago y Franco Figueroa (2001), pero que aún precisa de muchas más investigaciones.

${ }^{33}$ Dadas las dificultades que a veces existen para determinar el origen taíno o arahuaco de muchas de estas voces, así como los comunes procesos que experimentan en su incorporación al español americano, se ha optado por agrupar los indigenismos isleños bajo el marco general de lenguas antillanas.

${ }^{34}$ Aunque pueda parecer una cuestión de detalle, cabe mencionar que este término no presenta en la documentación el valor de 'guiso caldoso' (AML, 2010: s. v. pozole) o 'guisado que se prepara cociendo (...) maíz entero deshollejado y trozos de carne de puerco' (Morínigo, 1998: $s$. $v$. pozole), sino más bien el de 'bebida hecha de masa de maíz con azúcar o cacao', es decir el significado que el Diccionario de Mexicanismos registra bajo la entrada pozol (AML, 2010: s. v. pozol) y que - con la forma común pozole - Morínigo (1998: s. v. pozole) considera propio de Centroamérica; constituye, así, una muestra - y no única - de las coincidencias léxicas que se dan entre los países de América Central y Yucatán, que en muchos casos, además, individualizan esta variedad y establecen una marcada diferencia entre el léxico de la península y el resto de México. 


\begin{tabular}{|l|r|l|}
\hline Maya & $3(14 \%)$ & balché, patí, sacá \\
\hline Caribe & $1(5 \%)$ & piragua \\
\hline Cuna & $1(5 \%)$ & chicha \\
\hline Quechua & $1(5 \%)$ & chino $^{35}$ \\
\hline TOTAL & $21(100 \%)$ & \\
\hline
\end{tabular}

TABLA 2.-Indigenismos registrados en el corpus.

En realidad, tales resultados no son demasiado sorprendentes, sino que concuerdan con lo que hasta el momento se ha indicado acerca de la influencia de las distintas lenguas indígenas en la configuración léxica del español de América (Ramírez Luengo, 2007: 76-79). Quizá sea interesante resaltar, con todo, la coincidencia que en general se descubre entre estos datos y los que Polo Cano (2005: 192) señala para la Guatemala del siglo XVIII, donde también las voces nahuas y antillanas constituyen la mayoría —algo más del 60\% - y los mayismos aparecen de manera muy reducida, con apenas un $9 \%$ del total ${ }^{36}$.

A la luz, pues, de estas coincidencias en áreas geográficas dispares - aunque relacionadas desde muchos puntos de vista-, cabe interrogarse acerca del porqué de diferencias tan notables en cuanto al aporte léxico de las distintas lenguas. Por supuesto, la respuesta no resulta difícil de obtener, y tiene que ver, en el caso de los antillanismos, con su temprana incorporación al español y su generalización - más o menos rápida - por todo el Nuevo Mundo ${ }^{37}$; en el caso de los nahuatlismos, con el carácter de lengua general que adquiere este idioma,

35 Tal y como se ha advertido anteriormente, se sigue en este caso la opinión del DECH (19801991: s. v. chino), que considera este elemento como quechuismo que "se ha extendido hasta la América Central”, y que presenta en México la acepción de 'voz de cariño' con que se registra en el texto. Con todo, los mismos Corominas-Pascual expresan sus dudas acerca de sus orígenes andinos al indicar que "en estos casos no podemos estar seguros de no habérnoslas con homónimos".

${ }^{36}$ Esta escasa presencia de mayismos que afecta al español yucateco (escrito) de la Centuria Ilustrada no parece ser exclusiva de la época, habida cuenta de que los análisis que lleva a cabo Ramírez Quintana (2008) sobre documentación del siglo XVI ofrecen resultados tan exiguos -más allá de la onomástica, también representada de forma abundante en el corpus aquí estudiado: Otzcutzcab (doc. 107), Pocyaxam (doc. 90) o Tiab (doc. 114) en el caso de la toponimia; Andrés Chan (doc. 99), Esteban Tzuc (doc. 90) o Nicolás Chuc (doc. 139) en el de la antroponimia - que el autor se ve obligado a concluir que "la descripción de entidades nuevas presenta casi una presencia nula del léxico maya", y que "ha sido sorprendente la escasa presencia del léxico maya que describa la realidad cotidiana" (Ramírez Quintana, 2008: 1477, 1482). A resultados parecidos para el español actual — aunque referidos, en este caso, a Guatemala - llega Lipski (1996: 282), quien indica que "las lenguas mayas no han hecho aportaciones al español de Guatemala en proporción a su número".

37 A este respecto - y refiriéndose a la Nueva España del siglo XVI-, indica Lope Blanch (1990: 163) que "la mayoría de los antillanismos se documenta profusamente (...) como palabras 
con todo lo que eso conlleva para su generalización y empleo por amplias zonas de América y, en consecuencia, para la extensión de su léxico por distintas variedades del español del continente (Frago y Franco Figueroa, 2001: 43; Polo Cano, 2005: 194). Frente a estas circunstancias favorecedoras, el maya no constituye una de las primeraslenguasdecontactonitampocoadquiereelpapelpreponderanteenlasociedad colonial que le corresponde al náhuatl, de manera que no sorprende que - pese aserlalenguadeusohabitualenlazonaestudiada—suaporteléxicoenladocumentación resulte notablemente escaso ${ }^{38}$.

En cuanto a los campos semánticos en los que estos elementos pueden ser englobados, la clasificación empleada anteriormente para los americanismos ofrece los siguientes resultados:

\begin{tabular}{|l|r|l|}
\hline \multicolumn{1}{|c|}{ CAMPO SEMÁNTICO } & \multicolumn{1}{c|}{ CASOS } & \multicolumn{1}{c|}{ VOCES } \\
\hline Alimentación & $6(29 \%)$ & balché, chicha, chocolate, maíz, pozole, sacá, \\
\hline Enseres / utensilios & $5(24 \%)$ & batea, barbacoa, hamaca, jícara, petaca, \\
\hline Flora & $3(14 \%)$ & ceiba, copal, guano \\
\hline Agricultura & $2(10 \%)$ & milpa, zacate \\
\hline Vestimenta & $2(10 \%)$ & patí, tilma \\
\hline Organización social & $1(5 \%)$ & cacique \\
\hline Apelativos & $1(5 \%)$ & chino \\
\hline Transportes & $1(5 \%)$ & piragua \\
\hline TOTAL & $21(100 \%)$ & \\
\hline
\end{tabular}

TABLA 3.-Distribución de los indigenismos en campos semánticos.

Salta a la vista que, aunque cuantitativamente los datos de este corpus no son coincidentes con los de Mejías (1980: 22) o Polo Cano (2005: 190) —esto es, los porcentajes de indigenismos en los distintos campos semánticos no concuerdan-, sí que hay notables parecidos desde lo cualitativo o, si se quiere, desde el punto de vista de los propios campos semánticos en los que estos elementos aparecen, que resultan ser prácticamente los mismos tanto en el Yucatán del periodo aquí analizado como en la Guatemala de la Centuria Ilustrada o en el Nuevo Mundo del siglo XVII. Por otro lado $-\mathrm{y}$ al igual que se apuntaba para los

que habían obtenido ya plena carta de naturaleza en la lengua española", algo que corroboran los datos del Altiplano Central que aportan Company y Melis (2002), donde es posible descubrir voces como hamaca, maíz o piragua.

${ }^{38}$ A estos argumentos, Ramírez Quintana (2008: 1482) suma otros que considera válidos al menos para el siglo XVI: el prestigio de la lengua conquistadora, la necesidad de intérpretes, la traducción de textos y la presencia de lo que denomina "una lengua franca". 
americanismos_-, resulta también importante resaltar la diversidad de campos semánticos en los que se incorporan los préstamos de las lenguas indígenas, pues tal circunstancia pone de manifiesto la generalidad de este recurso a la hora de americanizar el léxico del español del Nuevo Mundo y, con ello, la trascendencia que posee en los procesos de dialectalización de este nivel lingüístico.

Por último, la escasísima atención que los estudiosos han prestado hasta el momento a la diacronía del español yucateco determina que en ocasiones la aparición de ciertos indigenismos en esta documentación constituya su primera datación, cuestión sin duda de cierto interés para comprender de forma más profunda cómo y en qué momento se va configurando el léxico de la región. Así pues, si bien es verdad que la práctica totalidad de tales indigenismos se localizan ya en los siglos XVI y XVII en obras como el DECH (1980-91), Mejías (1980) y en menor medida Andión (2004), el corpus ofrece las que por el momento son las apariciones más antiguas de los términos balché 'bebida fermentada que (...) preparan los indios de descendencia mayeana' (Santamaría, 1974: s. v. balché), presente en 1679 en Cauich (doc. 90); sacá 'atol en lengua mexicana, hecho de agua y maíz y bébese frío sin cocer ni calentar, ya entrado el día' (Barrera Vásquez, 1980), que aparece en Mérida en 1721 (doc. 118); y guano en su acepción de 'tipo de palma', que Corominas-Pascual (DECH: s. v. miraguano) recogen a finales del siglo XVIII en Puerto Rico y cuya datación adelantan estos textos yucatecos en prácticamente un siglo (Mérida, 1691; doc. 99) ${ }^{39}$.

\subsection{La configuración léxica del español yucateco de los siglos XVII y XVIII}

Una vez analizados americanismos e indigenismos como categorías solo parcialmente coincidentes, y a partir de los datos expuestos en las páginas anteriores, parece interesante intentar establecer ahora — siquiera de manera provisional- la configuración léxica que presenta el español yucateco de los siglos XVII y XVIII tal y como aparece reflejada en el corpus documental aquí analizado ${ }^{40}$.

\footnotetext{
39 También son estos ejemplos dataciones previas a las que presenta CORDE (consulta: 09/07/ 2014) para estos vocablos: en efecto, para balché la aparición más antigua es de apenas 1969, en texto de Miguel Ángel Asturias, mientras que guano 'tipo de palma' se encuentra ya en 1701 en la Historia de la Conquista de la Provincia del Itza - texto, pues, también yucateco, o al menos referido a la región - de Juan de Villagutierre Sotomayor; sacá, por su parte, no se descubre en el repositorio de la Real Academia.

${ }^{40}$ Habida cuenta de que la configuración léxica depende en buena medida de los campos semánticos atendidos y —especialmente relevante para el estudio diacrónico — de la tipología textual que compone el corpus de análisis, salta a la vista que las conclusiones que se establezcan a continuación no pretenden ser concluyentes, sino meros avances de una investigación que por fuerza exige el empleo de una documentación mucho más amplia.
} 
A este respecto, conviene recordar en primer lugar que se entiende por configuración léxica la 'preferencia que muestra una determinada variedad por una de las posibles estrategias (modificación/incorporación) que se emplean a la hora de dialectalizar el léxico'. En efecto, la necesidad de expresar la nueva realidad americana obliga al español hablado en el continente a adaptarse desde el punto de vista léxico a las nuevas circunstancias, y tal adaptación léxica se produce por medio de las ya mencionadas estrategias de modificación — esto es, partir del léxico existente para modificarlo formal o semánticamente y hacerlo útil para su nuevo ámbito de empleo-y de incorporación, que consiste en introducir nuevas unidades léxicas tomadas de otros sistemas lingüísticos. Por supuesto, ambas estrategias persiguen el mismo propósito y se emplean en todas las variedades del español americano, pero es interesante destacar al respecto que no todas las emplean en la misma proporción, esto es, que algunas de ellas se inclinan de forma predominante por la estrategia de modificación mientras que otras, sin embargo, optan mayoritariamente por la incorporación, probablemente por causas muy variadas que tienen que ver, en última instancia, con la historia sociodemográfica de cada una de las regiones dialectales.

Así pues, en el caso concreto que se está analizando en estas líneas se descubren 21 elementos que responden a la estrategia de incorporación ${ }^{41}$ frente a 27 que manifiestan la ya mencionada estrategia de modificación ${ }^{42}$, es decir, un $56 \%$ de estas y un $43 \%$ de las primeras. Se puede concluir a partir de estos datos, por tanto, que en el español yucateco de los siglos XVII y XVIII ambas estrategias para expresar la realidad de la región parecen tener un peso más o menos equilibrado, si bien con una ligera preferencia, de algo más de diez puntos porcentuales, por la estrategia de modificación, algo que sin duda se debe poner en relación, como se dijo anteriormente, con circunstancias muy variadas de carácter sociohistórico - relacionadas con la población hispánica que da lugar a la sociedad criolla yucateca, la integración más o menos fuerte de la población maya a esta sociedad criolla o las relaciones entre la península y el Altiplano Mexicano ${ }^{43}$, entre otrasque será necesario analizar más adelante con cierta profundidad.

${ }^{41}$ En concreto se trata de los siguientes: balché, barbacoa, batea, cacique, ceiba, chicha, chino, chocolate, copal, guano, hamaca, jícara, maíz, milpa, patí, petaca, piragua, pozole, sacá, tilma y zacate.

${ }^{42}$ En este caso, las voces son las siguientes: aloja, banda, cascarilla, ceibana, chorreado, cimarrón, contesto, doctrinero, embarro, embrocar, encomendero, enguanar, estancia, ingenio, isleño, ladino, largar, milpero, moreno, motón, pardo, pierna, ramada, ranchería, soguilla, tamarindo y zafar.

${ }^{43}$ A este respecto, quizá la muestra más evidente de tales relaciones sea la presencia de diversos nahuatlismos en la región, muchos de los cuales - como, por ejemplo, milpa, tilma o zacate, entre otros - se descubren, naturalmente, en las fuentes históricas del Altiplano (Company y Melis, 2002: s. v. milpa, tilma, zacate). Ahora bien, cabe mencionar que los vocablos compartidos entre las dos zonas no se reducen exclusivamente a los indigenismos —entre otros, también se descubre en el centro de México americanismos endohispánicos como estancia, ladino, limeta y los 
En todo caso, más allá de los datos concretos - y a la espera no solo de profundizar en las causas que determinan la situación reflejada en los textos, sino también de comparar esta situación con la que se puede dar en zonas cercanas como el ya mencionado Altiplano Mexicano o Guatemala-, lo cierto es que esta primera aproximación pone de manifiesto el interés que, en los estudios de historia del léxico del español americano, ofrece el análisis de la configuración léxica para comprender de forma más completa los diversos fenómenos que producen la dialectalización de este nivel lingüístico y, por tanto, la adquisición de la idiosincrasia que presenta en este punto el español del Nuevo Mundo.

\section{CONCLUYendo}

De este modo, el análisis que se ha llevado a cabo a lo largo de estas páginas permite ofrecer ya una serie de conclusiones de cierto interés acerca de la historia léxica del español de Yucatán, así como también de la metodología que se puede aplicar para un estudio diacrónico más profundo del vocabulario de esta lengua en sus variedades americanas.

Por lo que se refiere a esta última cuestión, el análisis aquí desarrollado evidencia una vez más la utilidad de la definición del mexicanismo que propone Company (2007: 28-29) no solo para la detección y determinación de estos elementos -y, generalizando, de los americanismos_-, sino también para un estudio detallado y riguroso de los mismos; en este sentido, la aplicación de un criterio único, el uso, para el establecimiento de las voces que forman parte de esta categoría constituye un aporte de primera magnitud, por cuanto evita los problemas y ambiguiedades que, en ocasiones, presentan otras definiciones del concepto.

Con todo, es necesario señalar que esta forma de entender el americanismo tampoco está exenta de problemas y dificultades, entre los que cabe indicar dos de notable importancia: desde el punto de vista práctico, que en ocasiones el investigador carece de ejemplificación histórica suficiente de un elemento como para poder establecer su uso - y, por tanto, su carácter de americanismo - en una época concreta; desde el punto de vista teórico, que esta perspectiva - y los procesos de extensión léxica que afectan al léxico- por fuerza obligan a tener en cuenta el carácter dinámico del concepto americanismo, con todas las consecuencias que tal hecho tiene para la investigación diacrónica de estos elementos, tal y como demuestran los ejemplos facilitados a lo largo de estas páginas.

regionalismos frijol o ingenio (Company y Melis, 2002: s. v. estancia, frijol, ingenio, ladino, limeta) —, si bien en lo que se refiere a los americanismos de origen hispánico es mucho más difícil, si no imposible, establecer las relaciones históricas de dependencia entre las distintas variedades regionales del español. Es importante señalar, con todo, que se trata de una tarea del máximo interés a la hora de entender de forma más profunda de qué manera y a partir de qué influencias se origina $\longrightarrow \mathrm{o}$ se va modificando históricamente— el español hablado en Yucatán. 
Por otro lado, y desde un punto de vista estrictamente dialectal, estas páginas aportan también una serie de datos de cierta relevancia para la historia del léxico que se emplea en el español yucateco de los siglos XVII y XVIII, los cuales pueden ser de cierto interés para la — todavía necesaria- reconstrucción diacrónica de esta variedad americana del español.

Así pues, cabe señalar, en primer lugar - y como no podía ser menos-, la existencia, en la documentación analizada, de americanismos de todos los tipos previamente establecidos, si bien con una distribución cuantitativamente no semejante, al predominar con mucho los que se han denominado puros y semánticos. Así mismo, se constata la presencia de indigenismos y elementos endohispánicos en ambos grupos, pero con un claro predominio de voces de origen indígena en los americanismos puros y de vocablos patrimoniales en los semánticos, muchos de los cuales, dicho sea de paso, se deben interpretar — como es habitual en estos casos- como marinerismos de tierra adentro (Frago, 2010: 59).

En cuanto a los campos semánticos en los que se descubren tales americanismos, parece relevante señalar que — frente a lo que en principio es previsible- no se circunscriben a realidades favorecedoras de la incorporación de estos elementos como la flora o la fauna, sino que aparecen en múltiples y muy variadas esferas de la vida yucateca, tales como la organización social, la industria/construcción, la alimentación, los enseres/utensilios o los apelativos; se demuestra, por tanto, que la americanización del vocabulario no es un hecho puntual, reducido a ciertos aspectos, sino más bien una auténtica reorganización de todo el sistema léxico del español, con todo lo que eso conlleva.

Por lo que se refiere a los indigenismos, son tres las cuestiones fundamentales que cabe destacar: en primer lugar, el hecho de que casi todos ellos se puedan interpretar como americanismos, incluyendo en este grupo algunos bien conocidos actualmente en España (tales como barbacoa o hamaca), lo que parece evidenciar su tardía expansión por las variedades europeas del español; en segundo lugar, y en relación con su etimología, el claro predominio de voces nahuas y antillanas entre los elementos detectados en la documentación y, al mismo tiempo, la muy escasa aparición de términos de origen maya, en consonancia con lo indicado por Ramírez Quintana (2008: 1477) para el español de esta misma región en el siglo XVI, o por Polo Cano (2005: 192) para otras de presencia maya - Guatemala - en esta misma época. Por último, es también interesante la incorporación de estos vocablos en campos semánticos variados — a manera de ejemplo, la alimentación, los enseres/utensilios, la flora o la vestimenta-, algo que demuestra la frecuencia de este recurso para la dialectalización del léxico americano en general, yucateco en este caso. Además, y quizá de menor relevancia, los textos aquí estudiados ofrecen también las que por el momento parecen ser las primeras dataciones de algunos de estos indigenismos, en concreto los mayismos balché (1679) y sacá (1721) y el antillanismo guano (1691). 
En otro orden de cosas, los datos extraídos de la documentación permiten llevar a cabo un intento de configuración léxica del español de Yucatán de los siglos XVII y XVIII: con la provisionalidad que exige un análisis tan puntual como el presente, se pone de manifiesto en él el empleo de las dos estrategias de configuración, pero con cierto predominio de la modificación sobre la incorporación, algo que sin duda se puede justificar a partir de numerosas razones sociohistóricas, pero que, en todo caso, será necesario estudiar más adelante de forma más minuciosa y con un corpus más amplio y variado desde el punto de vista tipológico.

En conclusión, se puede decir que el análisis llevado a cabo en estas páginas, más allá de los aspectos concretos ya señalados, pone en evidencia una cuestión de cierta relevancia: que en los siglos XVII y XVIII se está generando, si no lo había hecho ya antes, cierta especificidad en el léxico - tanto en lo que tiene que ver con las voces que se emplean como con los perfiles generales de este nivel lingüístico- que parece individualizar e identificar la variedad de español que se emplea en las tierras yucatecas. Será, por consiguiente, necesario comprobar si este dato tiene su correspondencia en otros niveles lingüísticos y, en el caso de que así sea, por qué precisamente en este momento se produce el nacimiento — si es que se puede definir así- de un habla tan fascinante y a la vez tan desatendida en la bibliografía como es, desde todos los puntos de vista, el español de Yucatán.

\section{APÉNDICE}

Como complemento de todo lo indicado a lo largo de estas páginas, se facilita la localización, en el trabajo de Melis y Rivero Franyutti (2008), de las voces analizadas en el presente estudio, así como el contexto de aparición de las mismas ${ }^{44}$.

- Acabalar (Doc. 150; Mérida, 1774): "Ha fornicado a todo su pueblo, y aquí viene a acabalar su obra".

- Aloja (Doc. 105; Maní, 1699): "Dándole diferentes aguas, como fueron alojas, limonada y agua de tamarindos".

- Balché (Doc. 90; Cavich, 1679): "Los dos indios que iban con él bebieron balché".

- Banda (Doc. 99; Mérida, 1691): "Se fue a la casa de guano, que está de la otra banda de dicha iglesia".

- Barbacoa (Doc. 118; Mérida, 1721): "Les vio que ponían los dichos ídolos sobre una barbacoa que servía de mesa, y allí les ofrecían maíz cocido, balché, chicha".

- Batea (Doc. 130; Mérida, 1735): "Dicha Isabel tomó una batea y la embrocó, y en el asiento que quedaba por la parte superior clavó unas tijeras".

- Botar (Doc. 118; Mérida, 1721): "Se las entregó a un cuñado suyo, llamado Basilio Uc, para que las botase al monte".

\footnotetext{
${ }^{44} \mathrm{Al}$ igual que se dijo en los ejemplos facilitados anteriormente, y dado que el interés de este trabajo es exclusivamente léxico, se modernizan la grafía y la acentuación de los fragmentos de texto seleccionados.
} 
- Cacique (Doc. 118; Mérida, 1721): "Es natural y vecino del pueblo de Sonotchel, donde había seis años fue cacique".

- Casamiento (Doc. 170; Mérida, 1792): "Te noticio el casamiento de Camilo Alpísar".

- Cascarilla (Doc. 121; Mérida, 1724): "En dichos altares ponían también cuatro jícaras de agua que hacían componer de cascarilla y miel, con copal encendido".

- Ceiba (Doc. 99; Mérida, 1691): "Se fue debajo de la ceiba que está frontero a dicha ermita".

- Ceibana (Doc. 153; Campeche, 1777): "Solo le ocurre por respuesta una cosa que ha visto en María de la Luz Rebolledo, conocida como la Ceibana".

- Chicha (Doc. 118; Mérida, 1721): "Les vio que ponían los dichos ídolos sobre una barbacoa que servía de mesa, y allí les ofrecían maíz cocido, balché, chicha".

- Chino (Doc. 170; Mérida, 1792): "Chinito: no me extiendo a escribirte".

- Chocolate (Doc. 105; Maní, 1699): "Les dio muy buen chocolate, sacando algunos platones de viscotelas".

- Chorreado (Doc. 106; Campeche, 1702): "Lo primero es hacerles chocolate todos los días, que llaman en esta tierra chorreado, que es chocolate de pobres".

- Cimarrón (Doc. 90; Cavich, 1699): "Estaba en la montaña entre los indios cimarrones".

- Colorado (Doc. 173; Mérida, 1794): "Dicho oficial iba a caballo, cuyo color tiraba a colorado".

- Contesto (Doc. 169; Mérida, 1792): "He visto la de vmd. y a su contesto digo que pienso no se dilatará vmd. por allá".

- Copal (Doc. 121; Mérida, 1724): "En dichos altares ponían también cuatro jícaras de agua que hacían componer de cascarilla y miel, con copal encendido".

- Curato (Doc. 140; Campeche, 1752): "Dándonos el ínterin de algunos curatos".

- Doctrinero (Doc. 105; Maní, 1699): "Fray Francisco de la Cámara, ministro y cura doctrinero".

- Embarro (Doc. 153; Campeche, 1777): "Con un palillo cavó el embarro del cerco de la casa".

- Embrocar (Doc. 130; Mérida, 1735): "Dicha Isabel tomó una batea y la embrocó, y en el asiento que quedaba por la parte superior clavó unas tijeras".

- Encomendero (Doc. 105; Maní, 1699): "Don Joan del Castillo y Toledo, encomendero de Indias".

- Enguanar (Doc. 139; Mérida, 1748): "Dijo que las jícaras de saca habían sobrado de lo que habían dado a algunos indios que le habían enguanado su casa".

- Enojado (Doc. 175; Mérida, 1795): "Declaraba que lo era en efecto, que por lo mismo se había sentido enojado".

- Estancia (Doc. 140; Campeche, 1752): "Una estancia de ganado mayor con todo lo a ella perteneciente".

- Foguerada (Doc. 105; Maní, 1699): "Dispusieron muchas fogueradas en la plaza contigua a las casas de hospicio".

- Frijol (Doc. 170; Mérida, 1792): "Te digo que los frijoles que sembré, se me van secando".

- Guano (Doc. 99; Mérida, 1691): "Se fue a la casa de guano, que está de la otra banda de dicha iglesia".

- Hamaca (Doc. 80; Mérida, 1660): "Lo prendió en un motón que estaba en una pared en que se cuelgan hamacas".

- Indio (Doc. 90; Cavich, 1679): "En compañía de un indio llamado Luis Che".

- Ingenio (Doc. 170; Mérida, 1792): "Te encargo no te descuides en tu ingenio".

- Isleño (Doc. 140; Campeche, 1752): "Se dio (...) providencia de notificar a los religiosos isleños".

- Jícara (Doc. 118; Mérida, 1721): "Colgando delante una jícara de maíz cocido que llaman sacá".

- Ladino (Doc. 74; Mérida, 1651): "Ladina en la lengua castellana".

- Largar (Doc. 99; Mérida, 1691): "Le largó la tilma y se escondió detrás de la pared de la cruz".

- Limeta (Doc. 139; Mérida, 1748): "Por qué se hallaba colgada una limeta con aguardiente".

- Maíz (Doc. 90; Cavich, 1699): "Hallando unas mazorcas de maíz viejas, se vino por el camino".

- Milpa (Doc. 173; Mérida, 1794): "Les causaba extrañeza que un caballero les hubiese pedido pozole en la milpa, cuando los de Mérida solían tomar chocolate". 
- Milpero (Doc. 173; Mérida, 1794): "En el camino emparejó el declarante con dos indios milperos que iban hablando".

- Moreno (Doc. 81; Campeche, 1661): "Es hijo de una morena libre".

- Motón (Doc. 80; Mérida, 1660): "Lo prendió en un motón que estaba en una pared en que se cuelgan hamacas".

- Pardo (Doc. 100; Mérida, 1691): "Hizo parecer ante sí a Gracia Gonzales, parda libre".

- Patí (Doc. 172; Mérida, 1792): "Te escribí remitiendo con él dos piernas de patí, y hasta ahora no he sabido de él".

- Petaca (Doc. 74; Mérida, 1651): "Tráeme mi reliquia que está en la petaca".

- Pierna (Doc. 172; Mérida, 1792): "Te escribí remitiendo con él dos piernas de patí, y hasta ahora no he sabido de él".

- Piragua (Doc. 140; Campeche, 1752): "Por no tener quinientos pesos (...), hizo su viaje en una piragua".

- Pozole (Doc. 173; Mérida, 1794): "Les causaba extrañeza que un caballero les hubiese pedido pozole en la milpa, cuando los de Mérida solían tomar chocolate".

- Quebrar (Doc. 99; Mérida, 1691): "Se la dejó porque no le quebrara algún hueso".

- Ramada (doc. 138; Mérida, 1748): "Oyeron que decían unos indios que estaban debajo de una ramada, sentados cada uno en su hamaca junto a una foguerada, estas palabras: 'nada hemos hecho"".

— Ranchería (Doc. 90; Cavich, 1679): "Prosiguieron su viaje por la montaña sin llegar a ranchería ninguna".

- Sacá (Doc. 118; Mérida, 1721): "Colgando delante una jícara de maíz cocido que llaman sacá".

- Soguilla (Doc. 134; Mérida, 1746): "Dijo que se le había perdido una soquilla de perlas".

- Tamarindo (Doc. 105; Maní, 1699): "Dándole diferentes aguas, como fueron alojas, limonada y agua de tamarindos".

- Taurete (Doc. 175; Mérida, 1795): "Se puso a mirar su espada que estaba tendida al frente sobre unos tauretes".

- Tilma (Doc. 99; Mérida, 1691): "Dijo que la dicha tilma que se le ha mostrado es suya".

- Zacate (Doc. 139; Mérida, 1748): "Se ejercita en vender zacate y leñas".

- Zafar (Doc. 99; Mérida, 1691): "Le zafó a este declarante el sombrero".

\section{BIBLIOGRAFÍA}

AML. Academia Mexicana de la Lengua (2010): Diccionario de Mexicanismos, México, Siglo XXI Alonso, Martín (1958): Enciclopedia del idioma. Diccionario histórico y moderno de la lengua española (siglos XII al XX), Madrid, Aguilar.

Alvar, Manuel (1990): "Nuevas notas sobre el español de Yucatán”, en M. Alvar, Norma lingüística sevillana y español de América, Madrid, Ediciones de Cultura Hispánica, pp. 141-178.

Andión, María Antonieta (2004): Los indigenismos en la Historia de las Indias de Bartolomé de las Casas, Madrid, Consejo Superior de Investigaciones Científicas.

Barrera Vásquez, Alfredo (1937): "Mayismos y voces mayas en el español de Yucatán”, Investigaciones Lingüísticas, 4, pp. 35-48.

Barrera Vásquez, Alfredo et al. (1980): Diccionario Maya CORDEmex, Mérida, CORDEmex.

Bolio Ontiveros, Edmundo (1931): Mayismos, barbarismos y provincialismos yucatecos, Mérida, Imprenta El Porvenir.

Company, Concepción (2007): El siglo XVIII y la identidad lingüística mexicana, México, Academia Mexicana de la Lengua / Universidad Nacional Autónoma de México.

Company, Concepción (2010): "Introducción”, en Academia Mexicana de la Lengua, Diccionario de Mexicanismos, México, Siglo XXI, pp. XV-XXIII.

Company, Concepción y Chantal Melis (2002): Léxico histórico del español de México, México, Universidad Nacional Autónoma de México. 
CDH. Real Academia Española: Corpus del Diccionario Histórico, en línea: <http://web.frl.es/ CNDHE/view/inicioExterno.view> [consulta: 11/07/2014].

CORDE. Real Academia Española: Banco de datos CORDE. Corpus Diacrónico del Español, en línea: http://corpus.rae.es/cordenet.html [consulta: 09/07/2014].

CREA. Real Academia Española: Banco de datos CREA. Corpus de Referencia del Español Actual, en línea: <http://corpus.rae.es/creanet.html> [consulta: 13/07/2014].

DAM. Asociación de Academias de la Lengua Española (2010): Diccionario de Americanismos, Madrid, Santillana.

DECH. Corominas, Joan y José Antonio Pascual (1980-1991): Diccionario crítico etimológico castellano e hispánico, Madrid, Gredos.

Donadío Copello, María (2005): "Algo acerca de los americanismos y las regiones dialectales", en C. Aráus Puente (coord.), Manual de lingüística hispanoamericana, II. Notas para un seminario sobre el español americano, Bogotá, Instituto Caro y Cuervo, pp. 83-141.

Espejo, Fernando (1999): El habla de Yucatán, Mérida, Yucatán en el Tiempo.

Frago, J. Antonio (1999): Historia del español de América, Madrid, Gredos.

Frago, J. Antonio (2010): El español de América en la Independencia, Santiago de Chile, Taurus.

Frago, J. Antonio y Mariano Franco Figueroa (2001): El español de América, Cádiz, Universidad de Cádiz.

Franco Figueroa, Mariano (1991): "El fondo léxico patrimonial: americanismos semánticos en documentos de los siglos XVI y XVII", Anuario de Lingüística Hispánica, 4, pp. 147-79.

García Fajardo, Josefina (1984): Fonética del español de Valladolid, Yucatán, México, Universidad Nacional Autónoma de México.

Gómez González, Alba (2013): El léxico boliviano del siglo XIX: análisis del Diario del Tambor Vargas, Trabajo de Fin de Grado inédito, Alcalá de Henares, Universidad de Alcalá.

Heredia, Carmen (1934): "Dialectología de Yucatán”, Investigaciones Lingüísticas, 2, pp. 371-380.

Hildebrant, Martha (1961): La lengua de Bolívar, I. Léxico, Caracas, Universidad Central de Venezuela.

Lipski, John (1996): El español de América, Madrid, Cátedra.

Lope Blanch, Juan M. (1987): Estudios sobre el español de Yucatán, México, Universidad Nacional Autónoma de México.

Lope Blanch, Juan M. (1990): "El léxico de la zona maya en el marco de la dialectología mexicana", en Juan M. Lope Blanch, Investigaciones sobre dialectología mexicana, México, Universidad Nacional Autónoma de México, pp. 59-132.

Mejías, Hugo A. (1980): Préstamos de las lenguas indígenas en el español americano del siglo XVII, México, Universidad Nacional Autónoma de México.

Melis, Chantal y Agustín Rivero Franyutti (2008): Documentos lingüísticos de la Nueva España. Golfo de México, México, Universidad Nacional Autónoma de México.

Michnowicz, Jim (2009): "Intervocalis voiced stops in Yucatan Spanish: a case of contactinduced language change?", en M. Lacorte y J. Leeman (coords.), Español en Estados Unidos y otros contextos de contacto: sociolingüística, ideología y pedagogía, Madrid/ Frankfurt: Iberoamericana/ Vervuert, pp. 67-84.

Michnowicz, Jim (2011): "Dialect Standardization in Merida, Yucatan: the case of (b d g)", Revista Internacional de Lingüística Iberoamericana, 18, pp. 191-212.

Mora Peralta, Idanely (2008): Topónimos y antropónimos del maya yucateco en documentos coloniales de los siglos XVI y XVII, Tesina de Licenciatura inédita, México, Universidad Nacional Autónoma de México.

Moreno de Alba, José G. (2007): Introducción al español americano, Madrid, Arco/Libros.

Morínigo, Marcos A. (1998): Nuevo Diccionario de Americanismos e Indigenismos, Buenos Aires, Claridad.

Patrón Peniche, Prudencio (1932): Léxico yucateco. Barbarismos, provincialismos y mayismos, México, Tipografía Tenoxtitlán. 
Pfeiler, Bárbara (1995): "Zur Prosodie des Spanischen in Yucatán, Mexiko", en K. Zimmermann (coord.), Lenguas en contacto en Hispanoamérica: nuevos enfoques, Frankfurt/Madrid, Vervuert/Iberoamericana, pp. 119-134.

Polo Cano, Nuria (2005): "Algunos indigenismos léxicos en el español de Guatemala del siglo XVIII", Res Diachronicae, 4, pp. 185-202, <http://resdi.net>.

Ramírez Luengo, José Luis (2007): Breve historia del español de América, Madrid, Arco/Libros.

Ramírez Luengo, José Luis (2011): "Apuntes sobre el léxico del español altoperuano en el siglo XVIII", Cuadernos de la Ilustración y el Romanticismo. Revista Digital del Grupo de Estudios del Siglo XVIII, 17, <http://revistas.uca.es/index.php/cir/issue/view/120>.

Ramírez Luengo, José Luis (2012): "El léxico en los procesos de dialectalización del español americano: el caso de la Bolivia andina", Cuadernos del Instituto de Lengua Española, 7, pp. 393-404.

Ramírez Luengo, José Luis (en prensa): "Aspectos metodológicos para el estudio histórico del léxico americano: conceptos, ejemplificación y tareas para el futuro", en J. C. Huisa Téllez (ed.), El léxico del español americano y su estudio histórico. Hacia la revisión de las fuentes.

Ramírez Luengo, José Luis (en prensa b): "Contacto interdialectal en la historia del léxico: los americanismos en la Relación de Aller (Móxos, Bolivia; 1668)", en Actas de las III Jornadas de Lingüística Hispánica. Fronteras y diálogos, Lugo, Axac.

Ramírez Quintana, Pedro Ángel (2008): "Caracterizadores léxicos del español colonial en Campeche: la lengua maya”, en C. Company y J. G. Moreno de Alba (eds.), Actas del VII Congreso Internacional de Historia de la Lengua Española, Madrid, Arco/Libros, vol. 2, pp. 1471-1483.

Ramírez Quintana, Pedro Ángel (2009): Documentos para la historia filológica del estado de Campeche. Periodo Virreinal, Tesis de Maestría inédita, México, Universidad Nacional Autónoma de México.

Ramírez Quintana, Pedro Ángel (2011): "Indigenismos léxicos en escritos de español sobre la Península del Yucatán: siglo XVI”, en M. H. Ruz y E. Peniche García (eds.), Del mar y de la tierra firme: miradas viajeras sobre los horizontes peninsulares, Campeche/ Mérida, Universidad Autónoma de Campeche/ Centro Peninsular en Humanidades y Ciencias Sociales UNAM, pp. 12-25.

Real Academia Española (1803): DRAE. Diccionario de la Lengua Castellana, $4^{\mathrm{a}}$ ed., Madrid, Viuda de Ibarra.

Real Academia Española (1979 [1726-39]): Diccionario de Autoridades (edición facsímil), Madrid, Gredos.

Real Academia Española (2001): DRAE. Diccionario de la Lengua Española, 22 ed., Madrid, Espasa-Calpe.

Rosenblat, Ángel (1967): "Contactos interlingüísticos en el mundo hispánico: el español y las lenguas indígenas de América”, en N. Polussen y J. Sánchez Romeralo (coords.), Segundo Congreso Internacional de Hispanistas, Nimega, Instituto Español de la Universidad de Nimega, pp. 109-154.

Santamaría, Francisco Javier (1974): Diccionario de mejicanismos, México, Porrúa.

Suárez, Víctor M. (1945): El español que se habla en Yucatán: apuntamientos filológicos, Mérida, Díaz Massa.

Terreros, Esteban de (1987 [1786-1788]): Diccionario castellano con las voces de las ciencias y las artes, Madrid, Arco/Libros.

Yager, Kent (1989): 'La '-m bilabial' en posición final absoluta en el español hablado en Mérida, Yucatán (México)", Nueva Revista de Filología Hispánica, 37, 1, pp. 83-94.

Fecha de recepción: 15 de septiembre de 2014

Fecha de aceptación: 19 de septiembre de 2014 